\title{
Place of Care Trajectories in the Last Two Weeks of Life: A Population-Based Cohort Study of Ontario Decedents
}

\author{
Danial Qureshi, MSc, ${ }^{1}$ Peter Tanuseputro, MD, MHSc, CCFP, FRCPC?, \\ Richard Perez, $\mathrm{PhD}^{3}$, and Hsien Seow, $\mathrm{PhD}^{4}$
}

\begin{abstract}
Background/Objectives: Place of death is a commonly reported indicator of palliative care quality, but does not provide details of service utilization near end of life. This study aims to explore place of care trajectories in the last two weeks of life in a general population and by disease cohorts.

Design/Setting: A retrospective population-based cohort study using linked administrative-health data to examine Ontario decedents between April 1, 2010 and December 31, 2012.

Measurements: Place of care trajectories in the last two weeks of life.

Results: We identified 235,159 decedents. Of which, 215,533 represented the major cohorts of our analysiscancer $(32 \%)$, frailty (29\%), and organ failure (31\%). Sixty-one percent of all decedents died in hospital-based settings. Place of care utilization trends show us a marked increase in use of palliative-acute hospital care $(13 \%-26 \%)$ and acute hospital care $(12 \%-25 \%)$ and a small decrease in community care use $(15 \%-12 \%)$ in the last two weeks of life. Those with cancer were the largest users of palliative-acute hospital care, while those with organ failure were the largest users of acute-hospital care.

Conclusions: Place of care trajectories show a marked rise in care in hospital-based settings from $29 \%$ to $61 \%$ in the last two weeks of life. Nearly half of all hospital deaths had palliative care as the main service provided. Place of care trajectories differ greatly by disease cohort. Exploring place of care trajectories in the last two weeks of life can illuminate end-of-life utilization patterns not evident when reporting solely place of death.
\end{abstract}

Keywords: community based care; end-of-life care; hospital-based care; palliative care; place of care trajectories; service utilization

\section{Introduction}

I

N THE PAST FEW DECADES, research on place of death has become extensively studied. ${ }^{1-8}$ Research consistently shows that the majority of individuals prefer to die at home..$^{9-12}$ Place of death has been established as a valid indicator of end-of-life quality, with home deaths and avoidance of hospital-based deaths being considered outcomes of high quality end-of-life care. ${ }^{13,14}$

An international study comparing place of death across 14 countries found that Canada was one of several countries which had the highest proportion of deaths occurring in hospital, for both cancer (67\%) and noncancer patients
$(59 \%) .{ }^{15}$ A seven-country cancer study of older patients dying with cancer found that Canada had among the highest proportion of deaths in acute care hospitals compared to the United States which had the lowest. ${ }^{16}$ However, because of the international attention to support more patients at home during end of life, policymakers increasingly also want to know whether patients are spending more days at home and fewer days in hospital near end of life. Yet existing place of death research only provides information on where an individual was at the moment of their death. This means that a patient who experienced multiple transitions in their care setting within the last few weeks of life-such as moving between home, Emergency Department, and then to

${ }^{1}$ Department of Health Research Methodology, Evidence and Impact, McMaster University, Hamilton, Ontario, Canada.

${ }^{2}$ Department of Medicine, Ottawa Hospital Research Institute, University of Ottawa, Ottawa, Ontario, Canada.

${ }^{3}$ ICES McMaster Site, Hamilton, Ontario, Canada.

${ }^{4}$ Department of Oncology, McMaster University, Hamilton, Ontario, Canada.

Accepted June 18, 2018.

(C) Danial Qureshi et al., 2018; Published by Mary Ann Liebert, Inc. This Open Access article is distributed under the terms of the Creative Commons Attribution Noncommercial License (http://creativecommons.org/licenses/by-nc/4.0/) which permits any noncommercial use, distribution, and reproduction in any medium, provided the original author(s) and the source are credited. 
hospital-is undifferentiated from a patient who was well supported at home until the day of death, when he/she was then hospitalized for pain or symptom control. Moreover, policymakers want to know whether any hospitalizations were appropriate, but prior research has not described whether late-life hospitalizations were providing palliative care. There has been emerging research focusing on place of care and place of death as different concepts. ${ }^{17,18}$ These studies, nonetheless, have limitations. Some only focus on cancer patients, lack a population-based data source, or investigate particular health services (e.g., emergency department visits only). ${ }^{19-27}$

To address these knowledge gaps, we sought to examine the place of care trajectories in the last two weeks of life among Ontario decedents, including all healthcare services used in a publicly funded health system. We also examined how place of care trajectories in the last two weeks of life differ by individual disease cohorts (frailty, organ failure, and cancer). We particularly chose to observe the last two weeks of life because it is a time period in which end-of-life healthcare service utilization dramatically increases, especially the use of hospitalbased services, which tend to peak in the last week of life. ${ }^{28}$ This research would provide a more comprehensive understanding of where patients are receiving end-of-life care.

\section{Methods}

\section{Study design and data sources}

We conducted a retrospective cohort study of Ontario decedents, capturing all deaths from April 1, 2010 to December 31, 2012. To identify all services used across several health sectors in the last two weeks of life, we used health card numbers to link multiple administrative databases held at the Institute for Clinical Evaluative Sciences. The databases included the: Vital Statistics Database (Office of the Registrar General-Deaths), which captured place, cause, and date of death; Registered Persons Database, which captured all demographic information, including sex, age, and postal code; Ontario Health Insurance Plan Claims Database, which captured all claims data for physician services in both inpatient and outpatient settings; Home Care Database captured publically-funded home care services; Discharge Abstract Database captured acute hospital care with and without palliative care involvement (identified using a previously derived comprehensive list of palliative care billing codes) ${ }^{29,30}$; National Ambulatory Care Reporting System captured all Emergency Department visits; Continuing Care Reporting System captured care provided in long-term care and complex continuing care (i.e., equivalent to subacute care settings); and Statistics Canada Census data captured income quintile and rurality using postal codes. ${ }^{31}$

Five distinct categories exist for causes of death as follows: terminal illness (e.g., cancer), organ failure (e.g., chronic heart failure), frailty (e.g., Alzheimer's disease), sudden death (e.g., accident), and other ${ }^{28,32-34}$; these have been validated in Canada. ${ }^{28,35}$ In this study, we refer to these categories as "disease cohorts." Decedents were assigned to a disease cohort based on the underlying cause of death code (ICD-10-CA diagnosis code_-see Supplementary Tables S1 and S2; Supplementary Data are available online at www.liebertpub.com/jpm) found in the vital statistics records. For clarity, we replaced the label "terminal illness" with "cancer" since the majority of individuals in this disease cohort had a cancer-related death. Note that decedents in the "sudden death" and "other" cohorts were excluded in our analyses due to their small numbers.

\section{Outcome of interest}

The primary outcome of interest was patients' place of care trajectories among the last two weeks of life. Use of healthcare services by each patient during their last two weeks of life was identified and confirmed using billing records and fee codes. Based on having any record of healthcare service use in the last two weeks of life, decedents were categorized according to the following hierarchy for place of care (to control for any potential overlap of sector use): (1) palliative-acute hospital care, (2) acute hospital care, (3) emergency department, (4) complex continuing care, (5) long-term care (i.e., nursing home), (6) home care, (7) home-based physician visit, (8) outpatient physician encounter, (9) and no health services. Using this hierarchy, a patient using both a home care service and a homebased physician visit on the same day would be categorized as a home care user for that specific day due to the order of ranking. Within acute hospital settings, place of care on any given day during the last two weeks of life was counted as a palliative care day (i.e., deemed palliative-acute hospital care) for the entire duration of stay when: a decedent had a preadmitting condition listed as palliative care or the most responsible diagnosis for the hospital stay was also palliative, the main service provider was palliative, or palliative care was consulted for the largest portion of their hospital stay. For all remaining palliative-acute hospital care encounters, only a single day of the hospitalization was counted as a palliative care day (e.g., individuals initially admitted as acute care patients but later received a palliative diagnosis at some point during their hospital stay). This approach captures officially and unofficially designated palliative care unit beds in hospital. Note that when we use the term "hospital-based care," we are referring to hierarchy rankings $1-4$, and when using the term "community-based care," we are referring to rankings 6-8 (i.e., not long-term care).

\section{Statistical analysis}

Descriptive statistics was used to compare cohort characteristics across the entire study population and by disease. These characteristics include the following: sex, age, income quintile, rurality, chronic diseases, number of comorbidities, and place of death. Using our hierarchy approach, we graphed place of care trajectories of the overall study population, showing the number of people in a particular setting on a day-by-day basis within the last two weeks of life. We also graphed individual place of care trajectories of three major disease cohorts (frailty, organ failure, and cancer), with no hierarchy intact, allowing us to visualize the total utilization of each place of care on a dayby-day basis within the last two weeks of life. Furthermore, we used mean and median statistics to describe place of care utilization in the last two weeks and last day of life. Ethics approval for this study was granted by the Ottawa Hospital Research Institute Ethics Board in Ottawa, Ontario, Canada.

\section{Results}

We identified 235,159 decedents during the study period. Our cohort was grouped into several disease cohorts: $32 \%$ as 
cancer, $31 \%$ as organ failure, $29 \%$ as frailty, $3 \%$ as sudden death, and $5 \%$ as other (see Table 1). Decedents with cancer, frailty, or organ failure comprised 215,533 (92\%) of the study population. Decedent characteristics were similar across all disease cohorts, with the exception of those in the frailty cohort (they had higher proportions of older females) and those in the sudden death cohort (they were younger with fewer comorbidities). Among the overall cohort, $\sim 80 \%$ of decedents were aged 65 years or older. Seventy-nine percent of decedents had three or more comorbidities with hypertension being the most prevalent disease, followed by osteoarthritis and cancer. Looking at disease cohorts, $68 \%$ of the organ failure cohort experienced a hospital-based death followed by $66 \%$ of those with cancer and $48 \%$ of those with frailty. The frailty cohort also had a higher percentage of long-term care deaths (35\%). Furthermore, the cancer cohort had a considerably higher percentage of individuals dying in a community-based setting (27\%) compared to those with organ failure (14\%) or frailty $(17 \%)$.

Figure 1 displays the place of care trajectories for the entire study population (includes all five disease cohorts). Two weeks before death, $29 \%$ of decedents were in hospital-based care; this grew to $61 \%$ of decedents in hospital-based care on their day of death, of which $43 \%$ were determined as palliative-acute hospital care. In the last two weeks, palliativeacute hospital care and acute hospital care settings had the largest and sharpest rise in utilization $(13 \%-26 \%$ and $12 \%-$ $25 \%$, respectively). Generally, there was a gradual decline in the percentage of patients residing in a community-based care setting with each day closer to death. We found very similar proportions and patterns in the place of care trajectories when we examined rural versus urban decedents, as well as the highest versus lowest income quintiles (see Supplementary Figs. S1 and S2).

Table 1. Cohort Characteristics

\begin{tabular}{|c|c|c|c|c|c|c|}
\hline Characteristic & $\begin{array}{c}\text { Cancer, } \\
\mathrm{n}(\%)\end{array}$ & $\begin{array}{c}\text { Organ failure, } \\
\mathrm{n}(\%)\end{array}$ & $\begin{array}{l}\text { Frailty, } \\
\text { n (\%) }\end{array}$ & Other, n (\%) & $\begin{array}{c}\text { Sudden death, } \\
\mathrm{n}(\%)\end{array}$ & $\begin{array}{l}\text { Total, } \\
\mathrm{n}(\%)\end{array}$ \\
\hline Overall & $75,657(32)$ & $72,363(31)$ & $67,513(29)$ & $11,784(5)$ & $7842(3)$ & $235,159(100)$ \\
\hline \multicolumn{7}{|l|}{ Sex } \\
\hline Female & $36,532(48)$ & $37,992(53)$ & $36,810(55)$ & $6489(55)$ & $2855(36)$ & $37,992(53)$ \\
\hline Male & $39,125(52)$ & $34,371(47)$ & $30,703(45)$ & $5295(45)$ & 4987 (64) & $34,371(47)$ \\
\hline \multicolumn{7}{|l|}{ Age } \\
\hline$<19$ & $172(.23)$ & $691(1)$ & $47(0.07)$ & 827 (7) & $435(6)$ & $2172(1)$ \\
\hline $19-44$ & $1886(2)$ & $1601(2)$ & 479 (1) & 332 (3) & $2636(34)$ & $6934(3)$ \\
\hline $45-64$ & $17,765(23)$ & 9878 (14) & 5931 (9) & $1172(10)$ & $2637(34)$ & $37,383(16)$ \\
\hline $65-84$ & $40,832(54)$ & $32,332(45)$ & $26,462(39)$ & $4188(36)$ & 1456 (19) & $105,270(45)$ \\
\hline$\geq 85$ & $15,002(20)$ & $27,861(39)$ & $34,594(51)$ & $5256(45)$ & $678(9)$ & $83,400(35)$ \\
\hline \multicolumn{7}{|l|}{ Income } \\
\hline Lowest & $16,014(21)$ & $17,288(24)$ & $15,637(23)$ & $2545(22)$ & 2008 (26) & $53,492(23)$ \\
\hline Low & $15,931(21)$ & $15,344(21)$ & $13,634(20)$ & $2317(20)$ & $1626(21)$ & $48,852(21)$ \\
\hline Middle & 14,698 (19) & 13,727 (19) & 13,059 (19) & $2086(18)$ & 1474 (19) & 45,044 (19) \\
\hline High & 14,621 (19) & $13,074(18)$ & 12,884 (19) & 2063 (18) & 1358 (17) & 44,000 (19) \\
\hline Highest & $13,996(18)$ & $12,136(17)$ & $11,850(18)$ & 1967 (17) & 1258 (16) & 41,207 (18) \\
\hline \multicolumn{7}{|l|}{ Rurality } \\
\hline Rural & $11,231(15)$ & $10,741(15)$ & 9558 (14) & $1286(11)$ & $1211(15)$ & 34,027 (14) \\
\hline \multicolumn{7}{|l|}{ Chronic diseases } \\
\hline Hypertension & $51,454(68)$ & $58,133(80)$ & $54,140(80)$ & $8649(73)$ & $2838(36)$ & $175,214(75)$ \\
\hline Osteoarthritis & $35,279(47)$ & $37,066(51)$ & $34,335(51)$ & $5848(50)$ & $2807(36)$ & 115,335 (49) \\
\hline Cancer & $70,383(93)$ & $16,073(22)$ & $12,938(19)$ & $2560(22)$ & 913 (12) & $102,867(44)$ \\
\hline Diabetes & $23,783(31)$ & $30,235(42)$ & $23,964(35)$ & $3876(33)$ & 1324 (17) & $83,182(35)$ \\
\hline $\begin{array}{l}\text { Congestive } \\
\text { heart Failure }\end{array}$ & 14,673 (19) & $32,266(45)$ & $27,958(41)$ & $4113(35)$ & $670(9)$ & $79,680(34)$ \\
\hline $\begin{array}{l}\text { Coronary heart } \\
\text { Disease }\end{array}$ & $18,006(24)$ & $26,035(36)$ & $28,039(42)$ & $3774(32)$ & 896 (11) & $76,750(33)$ \\
\hline Dementia & $8348(11)$ & $20,610(28)$ & $33,611(50)$ & $4056(34)$ & $534(7)$ & $67.159(29)$ \\
\hline COPD & $16,222(21)$ & $24,553(34)$ & $15,119(22)$ & $2590(22)$ & $704(9)$ & $59,188(25)$ \\
\hline Renal disease & 14,247 (19) & $21,991(30)$ & $15,970(24)$ & $3075(26)$ & $680(9)$ & $55,963(24)$ \\
\hline \multicolumn{7}{|l|}{ No. of comorbidities } \\
\hline 0 & $348(0.46)$ & $2049(3)$ & $1649(2)$ & $1166(10)$ & $1791(23)$ & $7003(3)$ \\
\hline $1-2$ & $17,884(24)$ & $10,195(14)$ & $10,818(16)$ & $1822(15)$ & $3249(41)$ & 43,968 (19) \\
\hline $3-5$ & $40,344(53)$ & $32,611(45)$ & $31,499(47)$ & $5114(43)$ & $2153(27)$ & $111,721(48)$ \\
\hline$\geq 6$ & $17,081(23)$ & $27,508(38)$ & $23,547(35)$ & $3682(31)$ & $649(8)$ & $72,467(31)$ \\
\hline \multicolumn{7}{|l|}{ Place of death } \\
\hline Hospital & $49,631(66)$ & $49,462(68)$ & $32,395(48)$ & $9191(78)$ & $3347(43)$ & $144,026(61)$ \\
\hline Long-term care & $5586(7)$ & $12,888(18)$ & $23,544(35)$ & 1539 (13) & $152(2)$ & 43,709 (19) \\
\hline Community care & $20,438(27)$ & $10,010(14)$ & $11,573(17)$ & 1054 (9) & $4342(55)$ & 47,417 (20) \\
\hline
\end{tabular}

COPD, chronic obstructive pulmonary disease. 


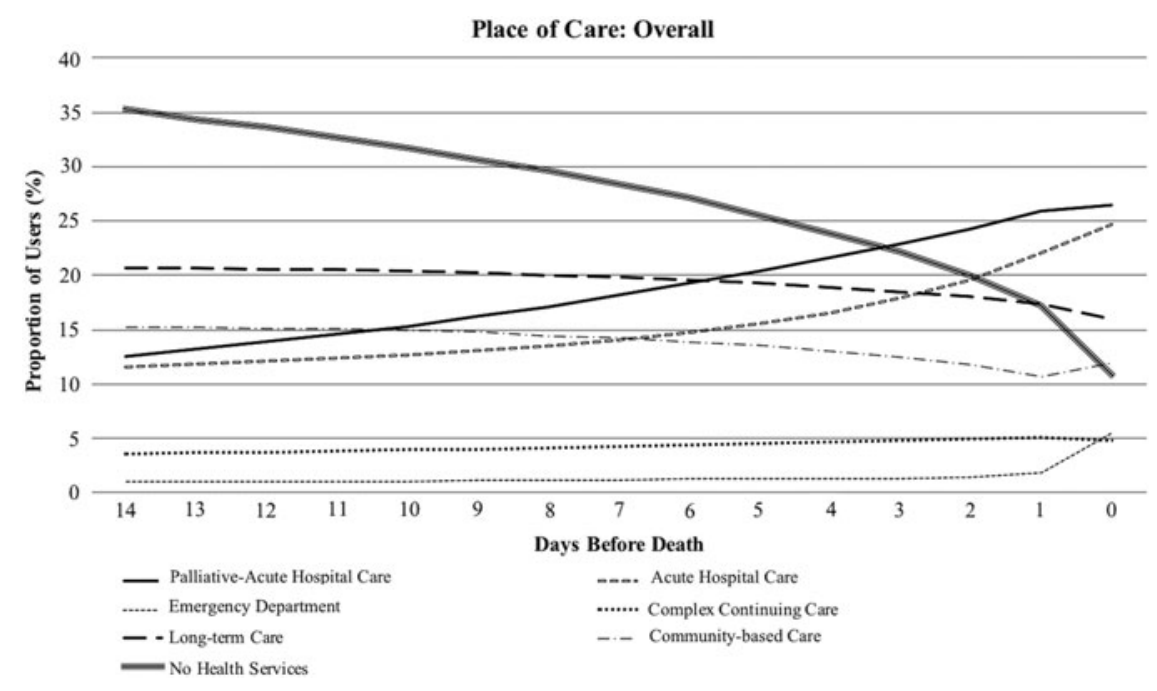

FIG. 1. Place of care trajectories in the last two weeks of life among overall study population. $n=235,159$ (cancer, organ failure, frailty, sudden death, and other). Hierarchy was applied here.

Figure 2 illustrates the place of care trajectory for three major disease cohorts (frailty, organ failure, and cancer) with no hierarchy intact. The cancer cohort had a considerably higher proportion of users for palliative-acute hospital care, complex continuing care, and all types of community-based care services. In contrast, across the last two weeks of life, the organ failure cohort had the largest proportion of acutehospital care users. The frailty cohort made up the lowest proportion of users of palliative-acute hospital care, acute hospital care, complex continuing care, and all types of community-based care, while having the highest proportion of long-term care users. Among community-based care services, a home-based physician visit was the least utilized service for all three cohorts in the last two weeks of life.

Table 2 displays the utilization among users of the various places of care, comparing the last two weeks of life and day of death. Thirty-four percent of the overall study population utilized acute hospital care (where no palliative care was provided) at least once in the last two weeks of life. Both long-term care users and complex continuing care users spent a large number of days in those settings (13.5 and 10.7 mean days, respectively). Palliative-acute hospital care and acute hospital care users also spent a large portion of the last two weeks of life in such settings (9.1 and 6.9 mean days, respectively). These trends were similar when examining each disease cohort separately. More than half of the overall study population used hospital-based care on their day of death. On the day of death, those with cancer comprised the largest proportion of palliative-acute hospital care users $(38 \%)$, while those with organ failure and frailty comprised the largest proportion of acute-hospital care users (32\% and 22\%, respectively).

\section{Discussion}

This study explores place of care trajectories in the last two weeks of life among the population-based cohort of decedents in Ontario, Canada. Only $29 \%$ of decedents were using hospital-based care two weeks before death, but this rose to $61 \%$ on day of death. Nearly half of that hospital-based care was palliative-acute hospital care. There are large disparities in the place of care trajectories by disease cohorts in the last two weeks of life. When comparing by disease cohort, those with cancer comprised the largest proportion of palliativeacute hospital care and complex continuing care users consistently throughout the last two weeks of life, whereas those with organ failure consistently comprised the largest proportion of acute hospital care users. The cancer cohort also consistently used more of all the community-based care services in the last two weeks of life. This is the first and largest population-based study that assesses place of care trajectories in the last two weeks of life of both cancer and noncancer decedents, which will be directly relevant to other countries with publicly funded healthcare systems.

Our population-based results around place of death and increased late-life hospitalizations are similar to those found in other international samples. ${ }^{27,36-38}$ The proportion of individuals dying in Ontario hospital-based settings are similar to the Canadian rate ${ }^{16}$ and other developed countries, such as Western Australia. ${ }^{26}$ Several other studies examined multiple places of care at end of life. Seow et al. measured the effect of community-based palliative care teams on places of care in the last 30 days for cancer patients, but did not describe a population-based sample that included noncancer patients. ${ }^{23}$ Teno et al. described changes in places of care among Medicare beneficiaries, but focused particularly on annual differences in hospital and nursing home stays in the last three months of life. ${ }^{25}$ Our study advances prior work by providing details about where individuals receive end-of-life care across multiple hospitaland community-based settings in the last two weeks of life.

Examining place of care trajectories provides information that is beneficial for quality improvement purposes. For instance, our results show that most patients were in the home and community two weeks before death, but many transferred to a hospital setting closer to death, for a mean of 8.6 days. It is important to note that not all hospitalizations are inappropriate: nearly half of the hospitalizations were provided with palliative care. Improvement activities might focus on preventing late-life hospitalizations that did not involve palliative care or on providing palliative care earlier or in community-based settings. The disparities we see 


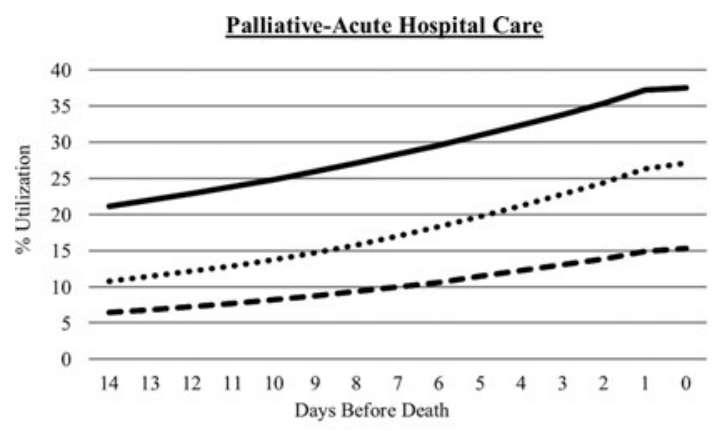

Acute Hospital Care

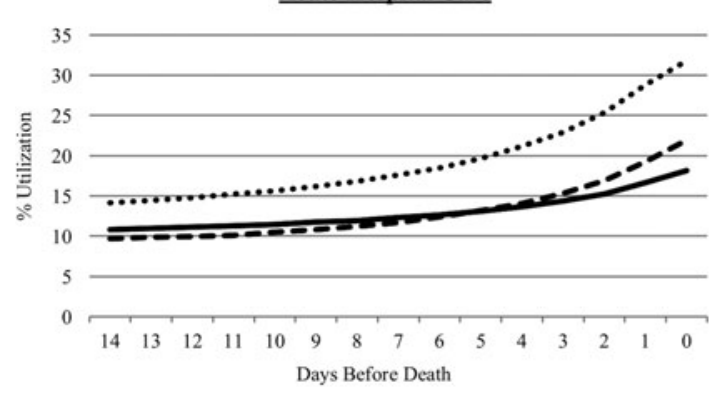

Emergency Department



Complex Continuing Care

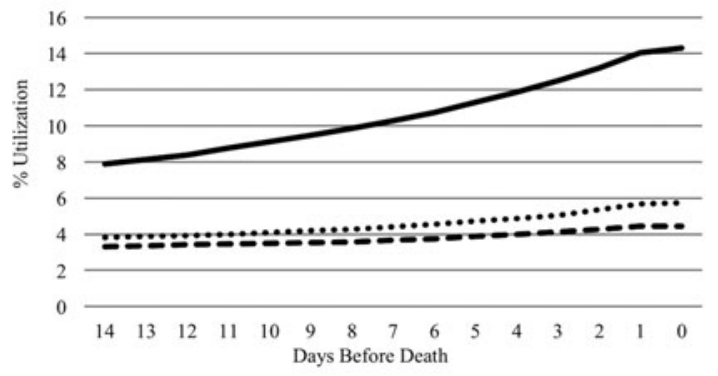

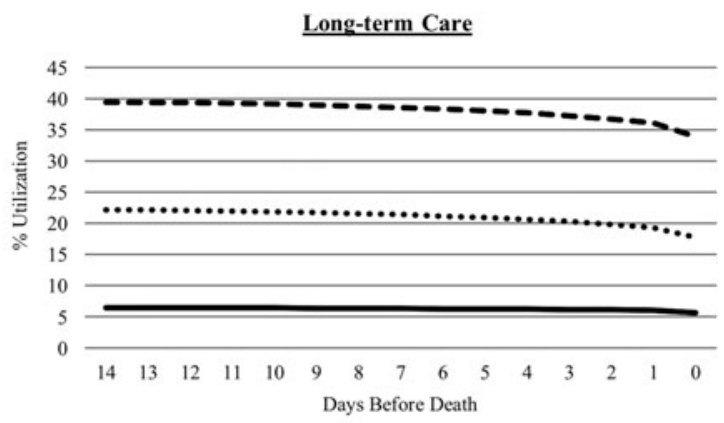



Home-based Physician Visit

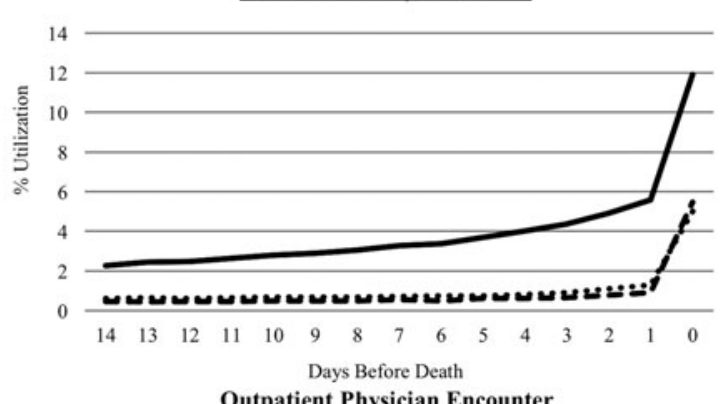

Outpatient Physician Encounter

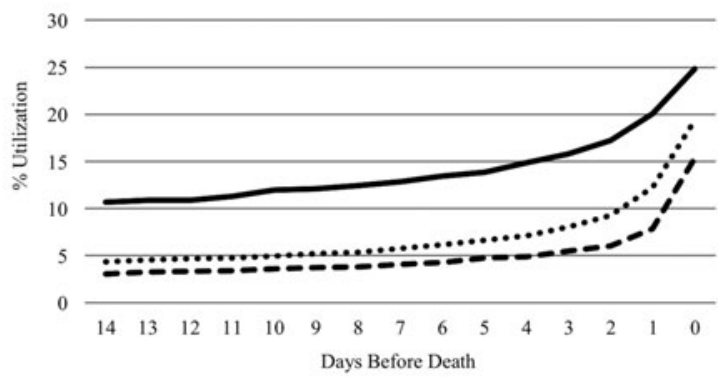

FIG. 2. Place of care trajectories in the last two weeks of life among three major disease cohorts (cancer, organ failure, and frailty). $n=215,533$. No hierarchy applied here.

among disease cohorts might be influenced by differential access to palliative care. Seow et al., recently examined variations in access to palliative care and found significant disparities among disease cohorts. They found that compared to organ failure and frailty decedents, those with terminal illness (mostly cancer) were significantly more likely to receive any palliative care, received more hospital and communitybased palliative care services, and initiated palliative care four times earlier. ${ }^{39}$ These findings suggest that palliative care services are still being under accessed by those with organ failure or frailty, which might require enhanced provider education. ${ }^{40,41}$
Our study has several limitations. First, using cause of death data to categorize decedents is an imperfect strategy since not everyone dying from a particular disease has the same trajectory of functional decline; unfortunately, we did not have additional data on functional status or symptom scores to examine place of care by functional trajectory and disease-specific cause of death separately. Moreover, our study does not provide an indication of the quality of care being delivered and only elaborates on place of care. Residential hospice was not included as a place of care setting since there is no central hospice database and thus cannot be 
Table 2. Place of Care Utilization Trends

\begin{tabular}{|c|c|c|c|c|}
\hline Place of care & Cancer & Organ failure & Frailty & Overall \\
\hline Total no. of users, $n(\%)$ & $75,657(32)$ & $72,363(31)$ & $67,513(29)$ & $235,159(100)$ \\
\hline \multicolumn{5}{|l|}{ Palliative-acute hospital care } \\
\hline No. of users, $n(\%)$ & $35,250(48)$ & $21,773(30)$ & $11,884(16)$ & $73,010(31)$ \\
\hline Among users: mean days, median (IQR) & $9.3,9(5-15)$ & $8.9,9(4-15)$ & $8.8,8(4-15)$ & $9.1,9(4-15)$ \\
\hline Among users: $\%$ using service on death date & 38 & 27 & 15 & 26 \\
\hline \multicolumn{5}{|l|}{ Acute hospital care } \\
\hline No. of users, $n(\%)$ & $22,282(28)$ & $29,296(37)$ & $19,736(25)$ & $79,226(34)$ \\
\hline Among users: mean days, median (IQR) & $6.6-6(2-10)$ & $7.2-6(3-12)$ & $6.7-5(2-11)$ & $6.9-6(2-11)$ \\
\hline Among users: $\%$ using service on death date & 18 & 32 & 22 & 25 \\
\hline \multicolumn{5}{|l|}{ Emergency department } \\
\hline No. of users, $n(\%)$ & $29,089(28)$ & $38,220(37)$ & $27,248(26)$ & $104,659(45)$ \\
\hline Among users: mean days, median (IQR) & $1.8-2(1-2)$ & $1.7-2(1-2)$ & $1.7-1(1-2)$ & $1.7-1(1-2)$ \\
\hline Among users: $\%$ using service on death date & 5 & 13 & 13 & 5 \\
\hline \multicolumn{5}{|l|}{ Complex continuing care } \\
\hline No. of users, $n(\%)$ & $11,285(55)$ & $4778(23)$ & $3442(17)$ & $20,393(9)$ \\
\hline Among users: mean days, median (IQR) & $10.7-14(6-15)$ & $10.4-13(5-15)$ & $11.1-15(6-15)$ & $10.7-14(6-15)$ \\
\hline Among users: $\%$ using service on death date & 14 & 6 & 5 & 5 \\
\hline \multicolumn{5}{|l|}{ Long-term care } \\
\hline No. of users, $n(\%)$ & $5262(10)$ & $17,117(32)$ & $27,911(52)$ & $53,268(23)$ \\
\hline Among users: mean days, median (IQR) & $13.5-15(14-15)$ & $13.3-15(13-15)$ & $13.8-15(15-15)$ & $13.5-15(14-15)$ \\
\hline Among users: $\%$ using service on death date & 6 & 18 & 34 & 16 \\
\hline \multicolumn{5}{|l|}{ Home care } \\
\hline No. of users, $n(\%)$ & $40,673(50)$ & $20,844(26)$ & $15,571(19)$ & $80,658(34)$ \\
\hline Among users: mean days, median (IQR) & $6.9-6(2-11)$ & $5.3-4(2-8)$ & $5.5-4(2-9)$ & $6.1-5(2-10)$ \\
\hline Among users: $\%$ using service on death date & 19 & 7 & 6 & 7 \\
\hline \multicolumn{5}{|l|}{ Home-based physician visit } \\
\hline No. of users, $n(\%)$ & $18,999(56)$ & $7524(22)$ & $6617(19)$ & $34,046(15)$ \\
\hline Among users: mean days, median (IQR) & $2.4-2(1-3)$ & $1.5-1(1-2)$ & $1.4-1(1-1)$ & $2.0-1(1-2)$ \\
\hline Among users: $\%$ using service on death date & 12 & 5 & 5 & 3 \\
\hline \multicolumn{5}{|l|}{ Outpatient Physician Encounter } \\
\hline No. of users, $n(\%)$ & $54,899(40)$ & $40,722(30)$ & $30,032(22)$ & $135,825(58)$ \\
\hline Among users: mean days, median (IQR) & $2.9-2(1-4)$ & $1.9-1(1-2)$ & $1.7-1(1-2)$ & $2.3-2(1-3)$ \\
\hline Among users: $\%$ using service on death date & 25 & 19 & 15 & 2 \\
\hline \multicolumn{5}{|l|}{ No health services } \\
\hline No. of users, $n(\%)$ & $36,384(32)$ & $34,981(31)$ & $28,023(25)$ & $112,097(48)$ \\
\hline Among users: mean days, median (IQR) & $6.0-5(3-9)$ & $8.8-9(5-13)$ & $10.0-12(6-14)$ & $8.5-9(4-13)$ \\
\hline Among users: $\%$ using service on death date & 6 & 9 & 14 & 11 \\
\hline
\end{tabular}

$\mathrm{IQR}$, interquartile range.

linked with the other administrative data. About 3000 individuals die in hospice each year (approximately one to three percent of overall deaths). However, most of these individuals use home care or palliative-acute hospital care-which is included in our study-before being admitted to hospice. We only include publicly funded homecare services. While we used methods to account for palliative care days in acute hospital settings during the last two weeks of life, we were unable to determine the number of palliative care days received by individuals in designated palliative care units within other places of care such as long-term care and complex continuing care. Future research should explore how place of care trajectories differ by local and geographical variations in palliative care provision; this can include rurality, access to palliative care, availability of hospital beds, and proximity to hospital care settings. It should also examine the impact of using community-based palliative care services among end-of-life patients on place of care and utilization.
In conclusion, this study examined place of care trajectories at the end of life in a general population and by distinct disease cohorts. It showed a marked increase in use of hospital-based care from $29 \%$ to $61 \%$ of the population in the last two weeks of life. Beyond place of death information alone, place of care trajectories can inform policymakers who aim to reduce inappropriate hospital use and costs at end of life and support more patients at home.

\section{Acknowledgments}

This research was supported by a research grant from the Ontario Ministry of Health and Long Term Care to the Health System Performance Research Network. This study used databases maintained by the Institute for Clinical Evaluative Sciences, which receives funding from the Ontario Ministry of Health and Long Term Care. The results, opinions, and conclusions highlighted in this article are those of the authors and are independent from the funding sources. 


\section{Author Disclosure Statement}

No competing financial interests exist.

\section{References}

1. Cohen J, Bilsen J, Addington-Hall J, et al.: Populationbased study of dying in hospital in six European countries. Palliat Med 2008;22:702-710.

2. Cohen J, Houttekier D, Onwuteaka-Philipsen B, et al.: Which patients with cancer die at home? A study of six European countries using death certificate data. J Clin Oncol 2010;28:2267-2273.

3. Currow DC, Burns CM, Abernethy AP: Place of death for people with noncancer and cancer illness in South Australia: A population-based survey. J Palliat Care 2008;24:144.

4. Gomes B, Higginson IJ: Factors influencing death at home in terminally ill patients with cancer: Systematic review. BMJ 2006;332:515-521.

5. Gruneir A, Mor V, Weitzen S, et al.: Where people die: A multilevel approach to understanding influences on site of death in America. Med Care Res Rev 2007;64:351378.

6. Houttekier D, Cohen J, Surkyn J, et al.: Study of recent and future trends in place of death in Belgium using death certificate data: A shift from hospitals to care homes. BMC Public Health 2011;11:228.

7. Murtagh F, Bausewein C, Petkova H, et al.: Understanding place of death for patients with non malignant conditions. Palliat Med 2012;26:409.

8. Tang ST, Huang E-W, Liu T-W, et al.: Propensity for home death among Taiwanese cancer decedents in 2001-2006, determined by services received at end of life. J Pain Symptom Manage 2010;40:566-574.

9. Bell C, Somogyi-Zalud E, Masaki K: Methodological review: Measured and reported congruence between preferred and actual place of death. Palliat Med 2009;23:482-490.

10. Billingham MJ, Billingham S-J: Congruence between preferred and actual place of death according to the presence of malignant or non-malignant disease: A systematic review and meta-analysis. BMJ Support Palliat Care 2013;3:144-154.

11. Gomes B, Calanzani N, Gysels M, et al.: Heterogeneity and changes in preferences for dying at home: A systematic review. BMC Palliat Care 2013;12:7.

12. Gomes B, Higginson IJ, Calanzani N, et al.: Preferences for place of death if faced with advanced cancer: A population survey in England, Flanders, Germany, Italy, the Netherlands, Portugal and Spain. Ann Oncol 2012;23:2006-2015.

13. Earle CC, Neville BA, Landrum MB, et al.: Trends in the aggressiveness of cancer care near the end of life. J Clin Oncol 2004;22:315-321.

14. Earle CC, Park ER, Lai B, et al.: Identifying potential indicators of the quality of end-of-life cancer care from administrative data. J Clin Oncol 2003;21:1133-1138.

15. Cohen J, Pivodic L, Miccinesi G, et al.: International study of the place of death of people with cancer: A populationlevel comparison of 14 countries across 4 continents using death certificate data. Br J Cancer 2015;113:1397-1404.

16. Bekelman JE, Halpern SD, Blankart CR, et al.: Comparison of site of death, health care utilization, and hospital expenditures for patients dying with cancer in 7 developed countries. JAMA 2016;315:272-283.

17. Agar M, Currow DC, Shelby-James TM, et al.: Preference for place of care and place of death in palliative care: Are these different questions? Palliat Med 2008;22:787-795.
18. O'Brien M, Jack B: Barriers to dying at home: The impact of poor co-ordination of community service provision for patients with cancer. Health Soc Care Community 2010;18: 337-345.

19. Casotto V, Rolfini M, Ferroni E, et al.: End of life place of care, health care settings and health care transitions among cancer patients: Impact of an integrated Cancer Palliative Care plan. J Pain Symptom Manage 2017;54: $167-175$

20. DeCaria K, Dudgeon D, Green E, et al.: Acute care hospitalization near the end of life for cancer patients who die in hospital in Canada. Curr Oncol 2017;24:256.

21. Langton JM, Reeve R, Srasuebkul P, et al.: Health service use and costs in the last 6 months of life in elderly decedents with a history of cancer: A comprehensive analysis from a health payer perspective. Br J Cancer 2016; 114:1293-1302.

22. Matter-Walstra K, Achermann R, Rapold R, et al.: Days spent in acute care hospitals at the end of life of cancer patients in four Swiss cantons: A retrospective database study (SAKK 89/09). Eur J Cancer Care 2017;26.

23. Seow H, Dhaliwal G, Fassbender K, et al.: The effect of community-based specialist palliative care teams on place of care. J Palliat Med 2016;19:16-21.

24. Au DH, Udris EM, Fihn SD, et al.: Differences in health care utilization at the end of life among patients with chronic obstructive pulmonary disease and patients with lung cancer. Arch Intern Med 2006;166:326-331.

25. Teno JM, Gozalo PL, Bynum JP, et al.: Change in end-oflife care for Medicare beneficiaries: Site of death, place of care, and health care transitions in 2000, 2005, and 2009. JAMA 2013;309:470-477.

26. Rosenwax LK, McNamara BA, Murray K, et al.: Hospital and emergency department use in the last year of life: A baseline for future modifications to end-of-life care. Med J Aust 2011;194:570-573.

27. Jakobsson E, Bergh I, Ohlen J, et al.: Utilization of healthcare services at the end-of-life. Health Policy 2007;82: 276-287.

28. Canadian Institute for Health Information: Health Care Use at the End of Life in Atlantic Canada. Ottawa, Canada: CIHI, 2011.

29. Tanuseputro P: Delivering care to those in need: Improving palliative care using linked data. Palliat Med 2017;31: 489-491.

30. Tanuseputro P, Budhwani S, Bai YQ, et al.: Palliative care delivery across health sectors: A population-level observational study. Palliat Med 2017;31:247-257.

31. Statistics Canada: Annual Demographic Estimates: Subprovincial Areas. Ottawa, Canada, 2010.

32. Gill TM, Gahbauer EA, Han L, et al.: Trajectories of disability in the last year of life. N Engl J Med 2010;362: 1173-1180.

33. Lunney JR, Lynn J, Foley DJ, et al.: Patterns of functional decline at the end of life. JAMA 2003;289:2387-2392.

34. Murray SA, Kendall M, Boyd K, et al.: Illness trajectories and palliative care. BMJ 2005;330:1007.

35. Fassbender K, Fainsinger RL, Carson M, et al.: Cost trajectories at the end of life: The Canadian experience. J Pain Symptom Manage 2009;38:75-80.

36. Kurtz ME, Kurtz J, Given CW, et al.: Utilization of services among elderly cancer patients-relationship to age, symptoms, physical functioning, comorbidity, and survival status. Ethn Dis 2005;15(2 suppl 2):S17-S22. 
37. Mukamel DB, Bajorska A, Temkin-Greener H: Health care services utilization at the end of life in a managed care program integrating acute and long-term care. Med Care 2002;40:1136-1148.

38. Solloway M, LaFrance S, Bakitas M, et al.: A chart review of seven hundred eighty-two deaths in hospitals, nursing homes, and hospice/home care. J Palliat Med 2005;8:789796.

39. Seow H, O’Leary E, Perez R, Tanuseputro P: Access to palliative care by disease trajectory: A populationbased cohort of Ontario decedents. BMJ Open 2018;8: e021147.

40. Huijberts S, Buurman BM, de Rooij SE: End-of-life care during and after an acute hospitalization in older patients with cancer, end-stage organ failure, or frailty: A sub- analysis of a prospective cohort study. Palliat Med 2016; 30:75-82.

41. Rosenwax L, McNamara B: Who receives specialist palliative care in Western Australia-and who misses out. Palliat Med 2006;20:439-445.

Address correspondence to: Hsien Seow, PhD

Department of Oncology

McMaster University

699 Concession Street, Rm 4-204

Hamilton, Ontario L8V 5 C2

Canada

E-mail: seowh@mcmaster.ca 